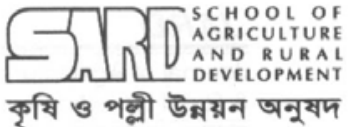

J ARD

Journal of Agriculture

\& Rural Development

\title{
Toxicological Study of Malic acid-Phthalic acid-Propane- 1,2-diol Copolyester
}

\author{
M. AMIRUL ISLAM ${ }^{*}$, SEFALY KHATUN ${ }^{2}$ AND M.A. BAKR ${ }^{3}$ \\ ${ }^{1}$ Open School, Bangladesh Open University, Gazipur, Bangladesh. \\ ${ }^{2 \& 3}$ Dept. of Applied Chemistry \& Chemical Technology, University of Rajshahi, Bangladesh.
}

\begin{abstract}
Malic acid-phthalic acid-propane 1,2-diol copolyester (MPPC) was administered intraperitoneally to the rats at a dose of $300 \mu \mathrm{g} \mathrm{rat}^{-1}$ day $^{-1}$ for 21 consecutive days to find out its harmful effect on rats. The gross general observations such as changes of body weight, hematological profiles, biochemical parameters of blood and the histopathology of liver, kidney, heart, lungs and spleen were investigated in control and experimental rats. The body weights of the rats were slightly increased. The changes of hematological and biochemical parameters were statistically insignificant. No abnormalities were found in the histopathology of the liver, kidney, heart, lung and spleen in the experimental group of rats when compared with control group of rats. From this study, it was inferred that malic acidphthalic acid-propane 1,2-diol copolyester would be used as a matrix for controlled and sustained release of drugs.
\end{abstract}

Key words: Malic acid-phthalic acid-propane 1,2-diol copolyester, sub-acute toxicity, haematological parameter, biochemical parameter, histopathology.

\section{INTRODUCTION}

The invention of synthetic polymer has brought a new era in the history of modern technology and the synthesis and development of biodegradable polymers is one of the brilliant aspects of polymer science at the present time. Many of the existing biodegradable carriers are linear polymers (Heller, 1980) and are being used for specialized application such as controlled release drug formulation (Löfgren et al., 1994, Löfgren et al., 1995, Gruvegard et al., 1998, Rosenberg et al. 1983), insecticide and pesticide carriers as well as non-toxic surgical implant materials. Poly(L-lactic acid) is a biodegradable polyester having good biocompatibility, it has been utilized as an useful biodegradable material in the medical and pharmaceutical fields. But the application scope of polyLA is limited because it is highly a crystalline polyester (Ouchi et al., 2000). Ongoing research in our laboratory is directed towards the synthesis and characterization of new biodegradable, flexible materials based on aliphatic polyester for controlled and sustained drug delivery (Bakr et al., 2004, 2006). Hydrolysis of labile ester linkages along the polymer backbone converts these materials into products that the human body can easily metabolize and eliminate them without adverse effects. Our aim is, therefore, to develop novel commercially viable polymers especially designed to degrade under controlled biological conditions and in this connection, we have attempted to synthesize MPPC polymer from malic acid, phthalic acid and propane 1,2-diol. The

* Corresponding author: Assistant Professor, Open School, BOU; Tel. 88-0172-0273830; E-mail: amirul202@yahoo.com

(C) 2006 School of Agriculture and Rural Development, Bangladesh Open University, All rights reserved. 
details of synthesis, characterization, hydrolytic degradation and drug release behaviour of MPPC have already been published (Bakr et al., 2002). It was reported that the copolyester is expected to be usable as matrix for controlled and sustained release of drugs. In order to develop and to establish the safety and efficacy level of a new drug, toxicity studies are very essential and no drug is used clinically without its clinical trial as well as toxicity studies. In this work, we report the subacute toxicity of the malic acid-phthalic acid-propane 1,2-diol copolyester (MPPC) in albino rats.

\section{MATERIALS AND METHODS}

Synthesis, characterization and toxicological study of MPPC on brine shrimp have been reported elsewhere (Bakr et al., 2002). Subacute toxicity of MPPC in albino rats is our present investigation.

Collection of experimental rats : Long Evan's rats of same sex (male) and age (adult) were collected from the Animal Resources Branch, International Center for Diarrhoeal Diseases Research, Bangladesh (ICDDRB).

Maintenance of the rats : The rats were kept properly in numbered iron cages individually and they were given ideal food (Hawk et al. 1993). They were kept in a clean animal house with an optimal room temperature $\left(25-30^{\circ} \mathrm{C}\right)$. The animals were maintained in this way for 15 days prior to administration of polymer and continued up to the end of the experiment.

Grouping of the rats : Rats were weighed individually and divided into two groups; group A (average body weight $135.25 \mathrm{gm} \mathrm{rat}^{-1}$ ) and group B (average body weight $132.62 \mathrm{gm} \mathrm{rat}^{-1}$ ), each comprising of 4 rats. Group A received vehicle only to act as control, while group B received MPPC.

Administration of sample : Malic acid-phthalic acid-propane 1,2-diol copolyester were dissolved separately in distilled water with the help of polyoxyethylene 20 sorbitan mono laurate (Tween-20)

in such a way that $0.3 \mathrm{ml}$ of final preparation contained $300 \mu \mathrm{g}$ of the polyester. The MPPC was administered to the rats of group $B$ intraperitoneally at a dose $300 \mu \mathrm{g} \mathrm{rat}^{-1}$ day $^{-1}$ respectively for 21 consecutive days.

Gross general observation after drug administration : The rats were observed daily very keenly to note the following features: Behaviour, CNS excitation, CNS depression, Food intake, Salivation, Diarrhoea, Muscular weakness.

Prior to sacrificing the animals, the body weights of each rat of groups A and B were measured before administration of the drug and after completion of the treatment.

Study of haematological profiles, biochemical parameters of blood and histopathology of liver, kidney, lung, heart and spleen: For haematological studies, blood was drawn from the tail veins of each rat in group $A$ and $B$ before the commencement of polymer administration. Blood smears were made on glass slides and stained with Leishmen reagent to perform TC, DC and platelet count. With the use of capillary tubes, blood was drawn from each rat to estimate the haemoglobin percentage by a hemocytometer. The tests were repeated on $7^{\text {th }}, 14^{\text {th }}$ and $21^{\text {st }}$ days after the compound administration.

For the determination of SGOT (Serum-glutamate-oxaloacetate-transaminase), SGPT (Serumglutamate-pyruvate-transaminase), SALP (Serum alkaline phosphatase), bilirubin, creatinine and urea, blood samples were collected separately from each of the control and experimental rat from their throat vein after sacrificing at the end of 21 days of polymer administration. The samples were then analyzed for biochemical parameters using the procedures and reagents as described in Enlehringer Mannheim GmbH Diagnostica (King and Armstrong,1934; Reitman and Frankel, 1957; Fawcett and Scott, 1960, and Coulombe and Favreau, 1963).

For histopathological studies of liver, kidney, heart, lungs and spleen were collected separately, sliced into pieces, fixed in formalin (10\%) for two days, processed, stained with Harris Haematoxylin and eosin reagent, mounted on glass slides with diphenyl xylene and observed under microscope at the Department of Genetics and Breeding, Rajshahi University, Bangladesh. 


\section{RESULTS AND DISCUSSION}

Synthesis of the Polymer: Five mixtures of malic acid and phthalic acid in mole combinations $(1.0+0),(0.9+0.1),(0.8+0.2),(0.7+0.3)$ and $(0.6+0.4)$ respectively were taken separately with 1 mole of propane 1,2-diol along with p-toluene sulfonic acid (approximately $0.4 \%$ of the total weight) as catalyst in a $250 \mathrm{ml} \mathrm{RB}$ flask which was connected to a Dean-Stark apparatus for eliminating water aziotropically with xylene as the reaction medium. The polymer obtained was pale orange colored, solid, sticky and slightly transparent at room temperature. In this way, five samples (I-V) were synthesized and then purified by precipitating them using a suitable non-solvent. Synthesis and drug delivery behavior of the copolyester have already been reported (Bakr et al., 2002).

Toxicological studies on brine shrimp nauplii : Toxicology is concerned with the deleterious effects of chemical and physical agents on living systems. Toxic effect on brine shrimp nauplii has been studied to evaluate the toxicity level of the synthesized compound. Brine shrimp lethality bioassay offers certain advantages over other cytotoxicity testing procedures. It is a rapid method utilizing only 24 hours, inexpensive and needs no special equipment. The results of toxicity of experimental samples, malic acid-phthalic acid-propane1,2-diol copolyesters (MPPC) and standard cellulose acetate phthalate (Cellulose acetate phthalate, a widely used enteric polymer, was taken as marker compound.) on brine shrimp have been reported else where.

Gross general observation : The group A (control) and group B (experimental) rats showed no signs of tremor, convulsions and reflex abnormalities. No muscular numbness of the hind and four legs, salivation or diarrhoea was observed. The food intake per day was also found normal. However, the body weights of all the rats were increased after administration of MPPC and the changes of body weights were found to be statistically insignificant which are shown in the Table I.

Table I : Effect of malic acid-phthalic acid-propane1,2-diol copolyester on body weight of rats after intraperitoneal administration.

\begin{tabular}{|c|c|c|c|c|c|c|c|}
\hline Group & $\begin{array}{c}\text { Dose level } \\
\mu \mathrm{gm} \mathrm{rat}^{-1} \text { day }^{-1}\end{array}$ & $\begin{array}{c}\text { Body weight } \\
\text { (in gm) before } \\
\text { drug treatment } \\
M_{1} \pm S_{1} n=4\end{array}$ & $\begin{array}{l}\text { Body weight } \\
\text { (in gm) after } \\
\text { drug treatment } \\
\mathrm{M}_{1} \pm \mathrm{SD}_{1} \mathrm{n}=4\end{array}$ & $\begin{array}{l}\text { Percentage } \\
\text { change }\end{array}$ & $\begin{array}{l}\text { Calculated } \\
\text { 't' value }\end{array}$ & $\begin{array}{l}\text { 't' value at } \\
5 \% \text { level of } \\
\text { significant }\end{array}$ & Remark \\
\hline \multirow{5}{*}{$\begin{array}{c}\text { A } \\
\text { Control }\end{array}$} & \multirow{5}{*}{$\begin{array}{c}300 \mu \mathrm{L} \text { of } \\
\text { Vehicle }\end{array}$} & 135.0 & 136.5 & \multirow{5}{*}{+1.293} & \multirow{5}{*}{+2.212} & \multirow{5}{*}{2.447} & \multirow{5}{*}{ NS } \\
\hline & & 137.5 & 139.0 & & & & \\
\hline & & 134.5 & 136.0 & & & & \\
\hline & & 134.0 & 136.5 & & & & \\
\hline & & $135.25 \pm 1.34$ & $137.00 \pm 1.17$ & & & & \\
\hline \multirow{5}{*}{$\begin{array}{c}\text { B } \\
\text { MPPC } \\
\text { Copolyester }\end{array}$} & & 130.0 & 132.5 & \multirow{5}{*}{+1.64} & \multirow{5}{*}{+1.62} & \multirow{5}{*}{2.447} & \multirow{5}{*}{ NS } \\
\hline & & 132.5 & 134.0 & & & & \\
\hline & $300 \mu \mathrm{gm}$ of & 135.0 & 138.0 & & & & \\
\hline & Copolyester & 133.0 & 134.7 & & & & \\
\hline & & $132.62 \pm 1.78$ & $134.80 \pm 2.01$ & & & & \\
\hline
\end{tabular}

$M_{1}$ and $M_{2}=$ Sample mean value

$S D_{1} \& S D_{2}=$ Standard deviations of control and experimental group respectively

$N=$ Number of rats

$+=$ Increase

NS = Not significant

Haematological profiles : The haematological profiles of the experimental rats were studied after intraperitoneal administration of the polymer to check the haematological disorders. Haematological profiles like total counts of RBC and WBC, differential count of WBC, platelet count and haemoglobin percentage were found normal before treatment and after $7^{\text {th }}, 14^{\text {th }}$ and $21^{\text {st }}$ days of treatment. No detectable changes were observed in the values of these parameters compared to that of the control groups. The results are shown in the Tables II and III. 
Table II : Haematological profile of group-A (Rat treated with vehicle)

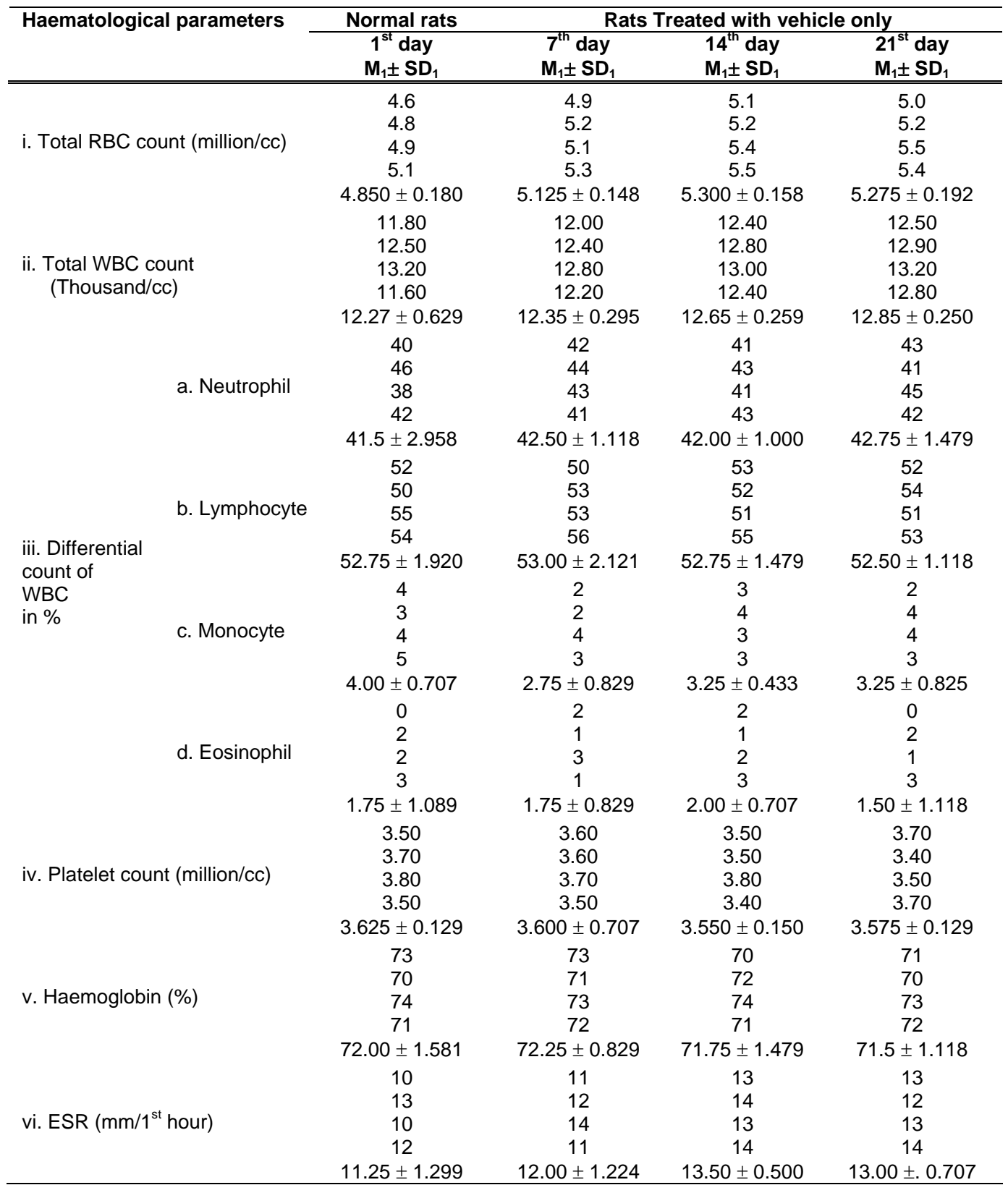

Monitoring the biochemical parameters : Biochemical parameters of blood e.g. SGOT, SGPT, SALP, serum bilirubin, serum creatinine, urea of both experimental and control rats were determined to check any change of these parameters due to the administration of polymer (MPPC) with respect to control rats. The results are presented in Table IV. It was found that most of the parameters were slightly increased with respect to that of the control groups but remained within the normal range. 
Table III. Haematological profile of group-B (Rats treated with malic acid-phthalic acidpropane1,2-diol copolyester)

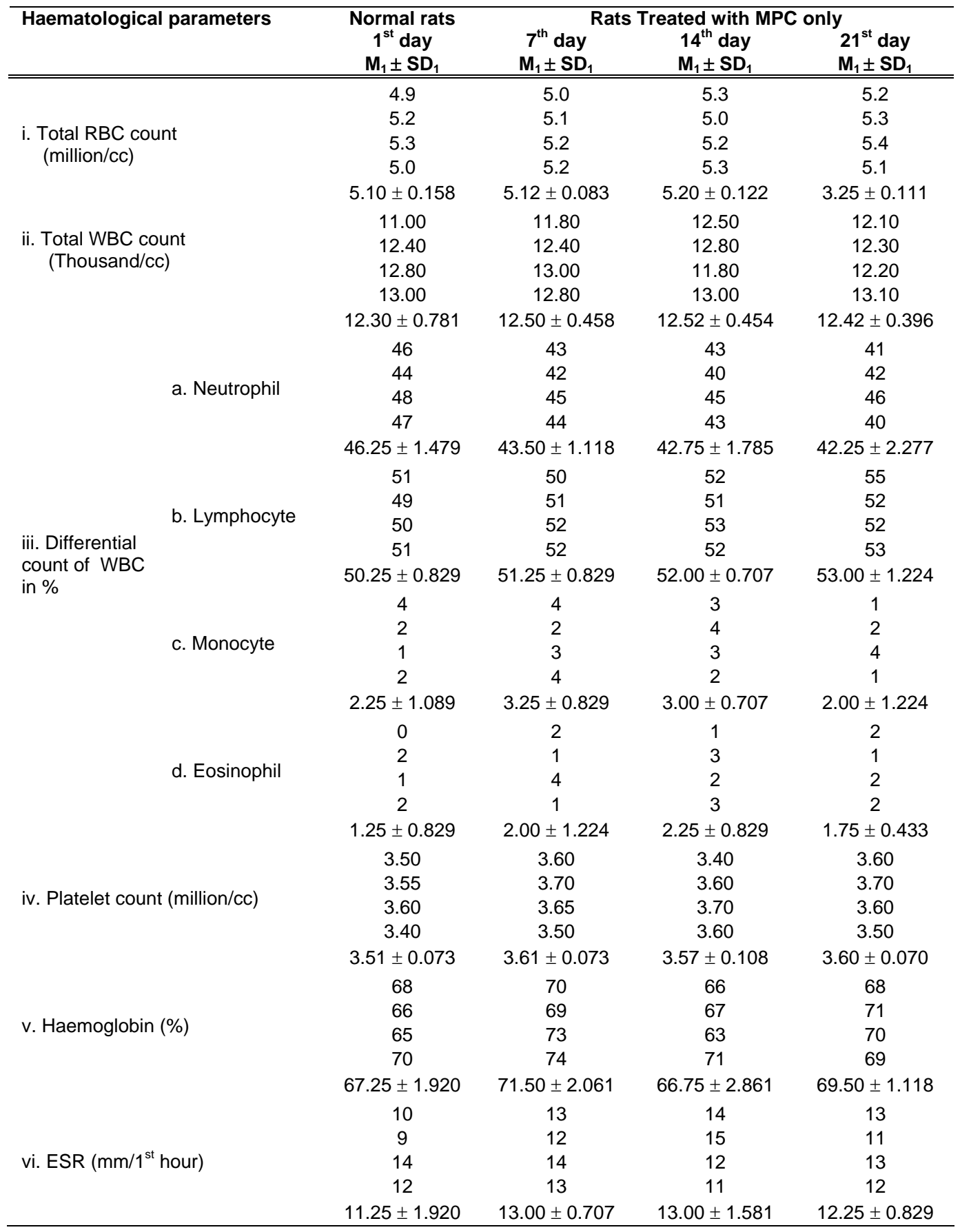

From the Table IV, it was found that the changes are also statistically insignificant. These results indicated that the compound has no adverse effects on liver and kidney functioning. 
Table IV. Effect of malic acid-phthalic acid-propane 1,2-diol copolyester on biochemical parameters of rat's blood after i.p. administration of $300 \mu \mathrm{g} \mathrm{rat}^{-1}$ day $^{-}$ 1 for 21 consecutive days.

\begin{tabular}{|c|c|c|c|c|c|c|}
\hline Biochemical Parameters & $\begin{array}{c}\text { Group-A, } n=4 \\
M_{1} \pm S_{1}\end{array}$ & $\begin{array}{c}\text { Group-B, } \mathrm{n}=4 \\
\mathrm{M}_{1} \pm \mathrm{SD}_{1}\end{array}$ & $\begin{array}{l}\text { Percentage } \\
\text { Change }\end{array}$ & $\begin{array}{l}\text { Calculated't' } \\
\text { value }\end{array}$ & $\begin{array}{c}\text { 't' value at } \\
5 \% \text { level of } \\
\text { significant }\end{array}$ & Remark \\
\hline Serum Glutamate & $\overline{99}$ & 10 & & & & \\
\hline Oxaloacetate Transaminase & 10 & 9 & & & & \\
\hline (SGOT) & 10 & 10 & +5.26 & +1.157 & 2. 447 & NS \\
\hline \multirow[t]{2}{*}{$(\mathrm{IU} / \mathrm{L})$} & 9 & 11 & & & & \\
\hline & $9.50 \pm 0.500$ & $10.00 \pm 0.707$ & & & & \\
\hline Serum Glutamate & 12 & 11 & & & & \\
\hline PyruvateTrans-aminase & 13 & 13 & & & & \\
\hline (SGPT) & 11 & 11 & +4.44 & +0.590 & 2.447 & NS \\
\hline \multirow[t]{2}{*}{ (IU/L) } & 9 & 12 & & & & \\
\hline & $11.25 \pm 1.479$ & $11.75 \pm 0.829$ & & & & \\
\hline Serum Alkaline & 43 & 48 & & & & \\
\hline Phosphatase (SALP) & 47 & 50 & & & & \\
\hline \multirow[t]{3}{*}{$(\mathrm{IU} / \mathrm{L})$} & 44 & 47 & +9.49 & +3.931 & 2. 447 & $\mathrm{~s}$ \\
\hline & 45 & 51 & & & & \\
\hline & $\begin{array}{c}44.75 \pm 1.479 \\
0.27\end{array}$ & $\begin{array}{c}49.00 \pm 1.581 \\
0.32\end{array}$ & & & & \\
\hline \multirow{3}{*}{$\begin{array}{l}\text { Serum Bilirubin } \\
\quad(\mathrm{m} \mathrm{mol} / \mathrm{L})\end{array}$} & 0.35 & 0.38 & & & & \\
\hline & $\begin{array}{l}0.36 \\
0.40\end{array}$ & $\begin{array}{l}0.39 \\
0.42\end{array}$ & +9.27 & +1.142 & 2.447 & NS \\
\hline & $\begin{array}{c}.0 .345 \pm 0.047 \\
0.85\end{array}$ & $\begin{array}{c}0.377 \pm 0.036 \\
0.90\end{array}$ & & & & \\
\hline \multirow{6}{*}{$\begin{array}{c}\text { Creatinine } \\
(\mathrm{mg} \%)\end{array}$} & 1.10 & 1.15 & & & & \\
\hline & 1.25 & 1.40 & +6.66 & +0.586 & 2.447 & NS \\
\hline & 1.30 & 1.35 & & & & \\
\hline & $1.125 \pm 0.175$ & $1.20 \pm 0.196$ & & & & \\
\hline & 39 & 42 & & & & \\
\hline & 42 & 45 & & & & \\
\hline \multirow[t]{3}{*}{ Urea (m mol/L) } & 37 & 39 & +9.49 & +2.128 & 2.447 & NS \\
\hline & 40 & 47 & & & & \\
\hline & $39.50 \pm 1.80$ & $43.25 \pm 3.031$ & & & & \\
\hline
\end{tabular}

$M_{1}$ and $M_{2}=$ Sample mean value

$S D_{1}$ and $S D_{2}=$ Standard deviations

$n=$ Number of rats

$+=$ Increase

NS = Non significant

$S=$ Significance

Table V. Effect of malic acid-phthalic acid-propane 1,2-diol copolyester on histopathology of rat's kidney, heart, lung, liver and spleen tissue after i.p. administration of $\mathbf{3 0 0}$ $\mu \mathrm{gm} \mathrm{rat}^{-1}$ day $^{-1}$ for 21 consecutive days.

\begin{tabular}{lllllll}
\hline \multirow{2}{*}{ Group } & \multirow{2}{*}{ Dose (i.p.) } & \multicolumn{4}{c}{ Histopathological change observed } \\
\cline { 3 - 6 } & Kidney & Heart & Lung & Liver & Spleen \\
\hline \hline A & $\mu$ rat $^{-1} \mathrm{day}^{-1}$ (Vehicle) & NAD & NAD & NAD & NAD & NAD \\
B & $\mu \mathrm{gm} \mathrm{rat}^{-1} \mathrm{day}^{-1}(\mathrm{MPPC})$ & NAD & NAD & NAD & NAD & NAD \\
\hline
\end{tabular}

NAD = No abnormality detected.

Histopathological studies : The histopathological studies of liver, kidney, heart, lung and spleen of both control and experimental rats were performed after intraperitoneal administration of the drugs for 21 consecutive days (Table V). No detectable differences in the histopathology of these organs of control and drug treated rats were observed when viewed under oil immersion objective. 
This indicates that the tested polymer MPPC has no effect on cellular structures, i.e, the polymer does not cause degeneration of the cells of these organs.

Acknowledgement: The authors would like to thank the Ministry of National Science and Technology, Bangladesh and the authority of the University of Rajshahi, Bangladesh, for providing financial assistance to carry out the project. They also express heartfelt thanks to Md. Asadul Islam, Lecturer, Department of Genetics and Breeding, Rajshahi University, and to Dr. Md. Anwar Habib, M.B.B.S., Lecturer, Dept. of Pharmacology, Rajshahi Medical College and Ph. D. Fellow, Department of Pharmacy, Rajshahi University for their full co-operation in performing the toxicological tests of the research samples.

\section{LITERATURE CITED}

Bakr M. A., S. Khatun and Islam, M. A. 2004, Drug Release Profile of Malic acid-Phthalic acid-Butane 1,4-diol Copolyester, Pakistan Journal of Scientific and Industrial Research, 47(4), 251-255.

Bakr M. A., K. Hasan, M.A. Islam, S. Khatun, M.A. Manan and Ara, K.S. 2006. In-vitro Drug Release Pattern of Maleic Acid-Succinic Acid-Propane 1,2-diol Copolyester, J. Polym. Mater. 23, 217-222.

Coulombe J. J., and Favreau, L. 1963. A new simple semi micron method for colorimetric determination of urea, J. Clin. Chem. 9, 102-108.

Fawcett J. K., and Scott, J. E., 1960. A new simple semi micron method for the determination of urea, J. Clin. Pathol. 13, 156-159.

Gruvegard M., Lindberg, T. and Albertsson, A.-C. 1998. J. Macromol. Sci. Pure Appl. Chem. A35: 885

Hawk, P. B., L. Oser and Summerson, W. H. 1993. Practical Physiological Chemistry, $13^{\text {th }}$ edition, Mc Graw Hill Book Company, USA.

Heller J., 1980. Controlled Release of Biologically Active Compounds from Bioerodable Polymers. Biomaterials 1, 51.

King, P. J. E., and Armstrong, A. R. 1934. A convenient method for determination serum and bile phosphatase activity, Cand. Med. Assoc. 31, 376-381.

Löfgren A. and Albertsson, A.-C. 1994. J. Appl. Polym. Sci. 52, 1327.

Löfgren A., A.-C. Albertsson, 1995. J. Macromol. Sci. Pure Appl. Chem. A32: 41.

Ouchi T., H. Miyazaki, F. Tasaka, A. Hamada and Ohya, Y. 2000. J. Polymer Preprints, 41(2), 1637.

Pramanick D. and Roy, T. T. 1980. Synthesis and Biodegradation of Copolymers from Citric Acid and Glycerol, Polymer Bulletin, 19, 365-370.

Reitman S., and Frankel, S. 1957. 'A colorimetric method for the determination of serum glutamic oxaloacetic and glutamic pyruvic transaminases', Am. J. Clin. Pathol. 28, 56-63.

Rosenberg H. B., J. Chang, G. E. Wnek, Linhardt and Langer, R. 1983. Bioerodable Polyanhydrides for Controlled Drug Delivery. Biomaterials. 4, 131. 